\title{
Applying quality of life in mental health social work practice
}

Kathy Martindale and Ross Phillips

Kathy Martindale is a Senior Lecturer at The University of Auckland, School of Counselling, Human Services and Social Work and is currently completing her PhD on subjective wellbeing.

Ross Phillips is the Director of Inclusion Solutions, based in Auckland and is committed to service; policy and workforce development that promotes increased experiences of social inclusion. Ross is a full member of the Aotearoa New Zealand Association of Social Workers

\begin{abstract}
The use of Quality of Life (QOL) indicators has become increasingly common in health and social services. This article proposes a framework to strengthen mental health social work practice by outlining subjective wellbeing, a component of the QOL construct. Following a discussion on the current policy influences on mental health service provision in Aotearoa New Zealand the QOL construct is outlined. The application of a QOL framework to mental health social work practice draws parallels between QOL principles and the current mental health philosophies of recovery, social inclusion and community care. The authors maintain that a focus on applying QOL in mental health social work will see its contribution to the mental health sector enhanced and its role and function more clearly described.
\end{abstract}

\section{Introduction}

Along with other professions, social work in mental health in Aotearoa New Zealand has been subjected to significant changes in policy directions over the past decade. These policy directions include a strong focus on community care, the promotion of positive mental health and wellbeing, delivering services to a recovery philosophy and the pursuit of social inclusion for service users (Mental Health Commission, 2007). This article examines these policy influences on mental health service provision and then suggests that the application of a Quality of Life (QOL) framework will assist social work practice in mental health to achieve the ambitions of current policy. We propose a QOL framework has the potential to allow a new perspective on social work practice in mental health, and to also be a positive influence on both service users and those who work in the field.

Mental health social work is practised in a broad variety of settings within New Zealand including district health board (DHB) delivered within acute inpatient and communitybased settings, community-based non-government organisations and primary care services. Practitioners work across a spectrum of services such as: infant, child and adolescent mental health, general adult, forensic, older persons, Maori and Pacific specific services, addiction services and dual disability services. Within DHB-delivered services social workers function within multi-disciplinary teams, as was the case with the Matthewson (2007) study. Within 
these teams social workers practise with roles and titles such as key-worker, care co-ordinator, care manager, support worker, rehabilitation co-ordinator and so forth. Commentators maintain that this, coupled with the marginal role of social work in decision making structures in mental health and the lack of real transition from medical models to social models, has meant that social work does not have a clearly articulated role and function under the new policy influences (Renouf \& Bland, 2005). We believe, from our practice experiences as a social worker and mental health consultant and a QOL researcher, that the QOL framework when applied to social work practice will begin to determine an evidence base that achieves current policy ambitions of recovery, inclusion and community care, whilst also providing mental health social work a clear description of role and function.

\section{Contemporary influences in mental health social work}

Many of the philosophies shaping mental health service provision, such as recovery, social inclusion and user-participation draw close parallels to social work values of wellness, social justice, empowerment, self-determination and community development (Reamer, 2005; Renouf \& Bland, 2005). Whilst it is expected that these influences would subsequently see a strengthening of the role and function of social work within mental health, Renouf and Bland (2005) indicate that this is not the case within Australia. Rather there has been no wellarticulated identification of the distinctive contribution of social work within current mental health service provision. The scarcity of recent New Zealand-based literature determining social work's role and function suggests a similar phenomenon here.

Mental health social workers often encounter situations of significant complexity (Ryan, Dowden, Healy \& Renouf, 2005), particularly where this concerns the ongoing health and wellbeing of individuals (i.e. assessing and managing risk, whilst also promoting individual self-determination). Social work theories, models, ethics and values abound and assist social workers in these environments to work in partnership with service users, helping them to make decisions in their best interests. Social work commitment to empowerment and client-focused care described by Ryan, et al. (2005) appear to be two particular values that reinforce social workers' abilities to manage complex and difficult situations. Similarly, the rights-based application of social work advocated by Connolly and Ward (2008) would ensure that social work interventions in mental health support service user wellbeing. Alongside this, the application of a QOL framework would contribute to enhance social work practice with a focus on service user wellbeing, as argued by Evans (2007).

\section{Recovery}

Recovery has been described as the first genuinely post-institutional service philosophy (Mental Health Advocacy Coalition, 2008), and has had a significant influence on mental health policy and service delivery in New Zealand (Mental Health Commission, 2007). New Zealand has been attributed as being the first country in the world to formalise 'recovery' as a national policy (Mental Health Commission, 2007). Recovery occurs when people can live well in the presence or absence of mental illness (Mental Health Commission, 1998). In keeping with the later discussion on subjective wellbeing, it is important to emphasise that within this definition it is up to the individual service user to determine what 'living well' means to them. That is, recovery is a subjective experience with an emphasis on living a satisfying, hopeful and contributing life that is determined by the person experiencing the mental ill health (Frese, Stanley, Kress \& Vogel-Scibilia, 2003). 
The recovery approach has its ideological origins in the self-help movement, the service user movement and psychiatric rehabilitation (Mental Health Commission, 2001). This requires mental health services to enable service users to identify and develop their own strengths and resources. Implications of this can include: communities becoming more inclusive, service users taking an active role in improving their lives and service delivery focused on making this possible (Mental Health Commission, 2001). The engagement of communities and including service users in community life has expressed itself in mental health service provision through the pursuit of social inclusion.

\section{Social inclusion, social exclusion and community care}

Whilst there is no one simple encompassing definition, in essence social inclusion can be described as the experience of full and valued participation in society. Conversely social exclusion occurs when a person is unable to fully participate in society, as described by the Ministry of Social Policy (2001). Adults with mental health issues have been identified as one of the most excluded groups in society (Mental Health Commission, 2009). Social exclusion has occurred largely due to stigma and discrimination, although literature suggests there are other contributing factors such as low expectations of people with mental health problems, a lack of responsibility by mental health services to address issues of exclusion, lack of employment and financial resources for service users, and barriers to engaging in, and accessing, community resources (Mental Health Commission, 2009).

A person's wellbeing is directly impacted upon by discrimination. Discrimination against people with a mental illness is a strong inhibitor of mental health service development and individual recovery. It is important to note that this discrimination not only occurs in the 'exclusionary society', where often the blame for social ills lie, but can occur within mental health services also. Mental health service delivery has historically been as concerned with containment and control as it has with emancipation and recovery (Rogers \& Pilgrim, 1996). Discrimination within mental health services leads to decision making by the mental health workforce without the involvement of service users. Service users have indicated that frequently the mental health system and those who work within it fail to give them respect, a protection of rights and equality (Mental Health Commission, 1998).

Deinstitutionalisation is inextricably linked with community care (Warren, 1996). The immediate assumption being if someone is removed from an institution then they will be cared for and become part of their regular community. However, there is a significant difference between care in the community and care by the community (O'Brien, 1993). Since the rise of institutional service delivery, and throughout the subsequent change to care in the community, there has been a strong reliance on professional mental health services as being the solution to people's problems. Formal mental health services have grown significantly. Statistics indicate that the funding of mental health services over the years from 1994 till 2003 increased by 174\% (Mental Health Commission, 2004). During this same period, service growth well exceeded population growth. While this was certainly advocated as being necessary by Blueprint (Mental Health Commission, 1998) due to the neglected state of funding prior to this, there has been little emphasis on delivering services in a way that decreases reliance on formalised service delivery. The Ministry of Health's national mental health and addiction workforce competencies released last year require that the mental health workforce has an increased focus on the mobilisation of existing community supports (Ministry of Health, 2008). Social work, with its long history of community development, is 
well positioned to take a lead in this activity. However, completing this requires balancing the tensions of building service user community connections and a sense of participation in community, with ongoing service delivery issues of containment, control, risk minimisation, and risk aversion (Phillips, 2008).

This article has evidenced the commonalities between the influences of recovery, social inclusion and community care with the social work functions of upholding rights, selfdetermination, participation and wellbeing. However, even with a policy direction that is consistent with some of social works traditional functions, social work is still not in a position of relative strength within clinical multidisciplinary teams, particularly where these are operating within a bio-medical framework (Renouf \& Bland, 2005). One way to ensure that practice is consistent with policies of recovery, inclusion and community care and of concurrently increasing social work influence in the mental health sector, is to apply a QOL framework to mental health social work practice.

\section{Quality of life and subjective wellbeing}

Quality of life is a complex multidimensional concept that has emerged as a critical philosophical and theoretical construct. It has been applied across a wide range of fields including, mainstream and special education, health care, mental health, intellectual disability and social services (Schalock \& Verdugo, 2002). The term QOL has been conceptualised in the literature in a variety of ways. It is commonly used as a generic term when evaluating or asking questions concerning 'the good life' or 'satisfaction with life', relative to a commonly held or implied standard of comparison experienced by most people in society. Consequently, QOL from this perspective centres on the degree of excellence of life that extends beyond the notions of mere survival or longevity, to focus on those aspects that make life particularly enjoyable, happy, fulfilling or meaningful, for an individual. Such aspects include but are not limited to, close relationships, achievements in life, self worth, work and a sense of belonging (Frisch, 2000).

Questions regarding the 'good life' have been used at varying levels of generality, from the assessment of community wellbeing to the specific evaluation of self. That is, in some contexts the term QOL refers to the quality of life of society as a whole, while in other instances it refers to the happiness or satisfaction of individuals within society. Questions regarding the 'good life' that focus on the specific evaluation of self, concern the experience of those individuals whose life is being assessed, and their subjective perception in relation to levels of satisfaction, either with their life-as-a-whole or across a number of life domains. This article deals predominately with QOL as it applies to the individual perspective.

A number of underlying assumptions exist that are critical for understanding quality of life. These have been summarised by Keith (2007, p.145) as:

- An individual's personal contexts (life domains) are critical to QOL;

- Life is experienced differently by different people and also experienced differently by the same people at different times (encompasses a lifespan approach);

- Quality of life is holistic, with various life domains interacting and therefore affecting each other;

- Personal choice, control and empowerment are important experiences of QOL; 
- Quality of life must have an appreciation of the significant role of an individual's subjective perceptions.

This latter point is particularly important as QOL is deeply embedded in the notion of individual perception and values. Allowing for this contributes to the identification and development of necessary supports and services that are relevant to the individual (Schalock \& Verdugo, 2002). As such, perceptions and values or the subjective view of the individual are recognised as key facets of quality of life by most contemporary researchers. Thus, for individuals and researchers, quality of life has come to imply a notion of the pursuit of excellence in common human values, and is generally associated with feelings of wellbeing, positive social involvement and opportunity to reach personal potential (Schalock et al., 2002). Such an approach is highly relevant and shares common synergy with the values and practice of social work and in particular mental health social work practice.

\section{Domains}

As mentioned, the application of a QOL framework involves a whole life perspective. It also comprises a number of 'core life domains' that can be viewed separately or aggregated to represent life-as-a-whole. While there is considerable debate in the literature regarding the composition of the QOL core domains, recent consensus was reached from a broad-based international research group, that eight core life domains explain quality of life as a whole (Schalock, et al., 2002). These domains include emotional well-being, material well-being, interpersonal relations, personal development, physical well-being, self-determination, social inclusion and rights (Schalock, et al., 2002). Core life domains represent the most important aspect of a person's life and thus, when described or measured are considered to describe the quality of a person's whole life. These core domains can be viewed as complementary to the previously indicated aspects of recovery, inclusion and community care.

The application of the QOL framework by measuring domain satisfaction provides a fuller picture regarding the components of a person's life that either contribute to or detract from a life of quality (Campbell, Converse, \& Rodgers, 1976; Diener, 1984). In addition, assessing satisfaction across life domains informs the social work practitioner, where and how services can intervene in order to achieve health and wellbeing outcomes. Thus, from this perspective the measurement of domain satisfaction provides a diagnostic tool to inform intervention strategies.

\section{Subjective wellbeing}

A further multidimensional aspect of quality of life is the distinction between objective and subjective quality of life indicators. Objective indicators generally refer to measured environmental conditions that provide normative values of any given group in society (Andrews \& Withey, 1976). An important distinction here is objective QOL indicators are easy to define and quantify (i.e. can be counted) and do not rely on an individual's perception; rather they simply reflect the objective circumstances of an individual's life (Diener \& Suh, 1997; Schalock \& Felce, 2004). The range of objective QOL indicators is unlimited and includes measures such as employment, life expectancy, standard of living, school enrolments, access to and affordability of housing and health services, voting rates, crime rates, and so forth. However, as argued by various authors (Campbell, Converse, \& Rodgers, 1976) objective QOL indicators alone, do not accurately reflect people's experience of wellbeing, as these indicators overlook how the experience of the measured indicators alters how people feel 
about their circumstances. Objective indicators alone are very poor predictors of subjective wellbeing (Cummins, 1998). In that, the relationship between objective indicators and perceived wellbeing is only modest at best (Schalock \& Verdugo, 2002).

The most commonly used global term to describe how people generally feel about their life is 'subjective wellbeing'. Subjective wellbeing is described in the literature as consisting of three interrelated components: life satisfaction, pleasant affect and unpleasant affect (Diener \& Lucas, 1999; Diener, Suh, \& Oishi, 1997; Headey \& Wearing, 1992). Subjective wellbeing refers to the evaluations that individuals make about their lives, either as cognitive judgements of life satisfaction, or affective evaluations of moods and emotions, or a combination of both (Diener \& Lucas, 1999) and captures the experiences of a person's life that are important to them, rather than merely the indirect measures of satisfaction that objective QOL indicators provide. The implication for social workers is the ability to understand subjective wellbeing on an individualised basis and consider those factors in a person's life where social work interventions are likely to have a significant impact on the person's satisfaction or happiness with life-as-a-whole.

\section{Applying a quality of life framework}

A review of the literature suggests six common themes for practitioners to consider when applying a QOL framework in their practice (Brown \& Brown, 2003; Brown \& Brown, 2005; Keith, 2007). These are summarised as:

- begin where the person places most importance;

- support actions that increase personal satisfaction and decrease dissatisfaction;

- encourage and support empowerment and enablement;

- account for the views of others;

- improve the individual's self image and self-belief;

- consider holistic aspects of the person's life.

The following section will now address each of those themes and the implications for mental health social work practice.

The first theme considers the need to begin with the quality of life core domains, where the individual places the most importance. There is a requirement that social workers are prepared to be led by the person and focus on what matters most to them. This means the development of recovery plans and pursuing recovery goals in a way that is determined by the service user. It is necessary to invest time to develop trust and a therapeutic relationship, so that the service user is able to identify QOL goals and develop plans with social workers to achieve them. In applying a QOL framework it is important that life goals are determined by the person and not determined by the subjective values of the mental health social worker.

The second theme involves the requirement to support actions that increase personal satisfaction and decrease dissatisfaction across core life domains deemed important to the service user. Social workers need to develop a good understanding with service users about the aspects of their lives that engender subjective wellbeing. Once determined, social workers then need to purposefully assist people to pursue activities that increase satisfaction. Where 
contact with mental health services causes dissatisfaction (e.g. through pressures of compulsion, containment, control and medication), social work has a role to advocate for positive change within their own organisations and the broader mental health service system.

The third theme of applying a QOL framework is to encourage and support empowerment and enablement. Social work has strong values of empowerment and self-determination (Reamer, 2005). Working with service users in an empowering way that encourages self-determination has been prescribed as a requirement of all mental health service staff (Ministry of Health, 2008).

Accounting for the views of others and including the service user's natural supports is a further requirement of applying QOL. However, this should not occur as a replacement for the service user's voice, but rather a recognition that understanding how to achieve quality of life for someone can be contributed to by people who know them well and care for them. When developing recovery plans and working with service users, social workers should endeavour to identify and involve the person's family / whanau and significant others. This application of QOL draws strong parallels to the requirements of service delivery focused on promoting social inclusion. Participation in family/ whanau and community life is a key focus of inclusive services. Where social workers increase their focus on supporting service users to strengthen their informal support networks, this effort will, in all likelihood contribute to a greater QOL experience for the service users they work with.

The next theme concerns the need to practice in a manner that improves an individual's self-image and self-belief. Research indicates that increased self-esteem and self-efficacy are associated with tangible QOL improvements, as were positive changes in social support (Evans, 2007). Encouraging people, holding and promoting a sense of optimism or hope are critical aspects of a recovery-focused service. Achieving this requires intentional social work interventions, aimed at improving the sense of self-worth, belief and hope that an individual has. The implication is that social workers within mental health have to be able to work with individuals in a recovery coaching and enabling capacity. Applying the core social work value of unconditional positive regard will also increase the likelihood of improving service users' self-image and self-belief.

The final theme for the practical application of QOL is encompassed within the need to consider holistic aspects of a person's life; their environmental, cultural and social interconnections. Understanding and working with service users within their social and community contexts is particularly important. Moving beyond the bio-medical response to illness requires consideration of all aspects (i.e. life domains) of a person's life. It also requires social workers to emphasise practice that is inclusive of, and meets the needs of, other people within the service user's community. Working within communities means supporting service users to engage in roles that are valued by the person and by the wider community to which they belong. This can include having a paid job, being a neighbour, enjoying friendships, engaging in recreational and leisure activities. 'Our Lives in 2014' (Mental Health Commission, 2004a, p.12) expresses a vision for service user status within communities when it states: (service users)

...whanau, communities and services work together to ensure we belong, have a liveable income, and have access to education, work and decent housing ... We have equal opportunities 
to participate in politics, legal processes, cultural events, recreation, sports, the arts, religion and philanthropy.

Social work interventions that are targeted at achieving this vision would be consistent with this final application of QOL.

Furthermore, Evans (2007) asserts a range of key messages for mental health services in relation to the QOL of service users. She states that QOL improvements for service users are both achievable and important to measure. By measuring and understanding domainspecific evaluations of subjective QOL, services can target interventions to improve outcomes within the specific domains relevant to the service user. Additionally, services may need to target specific life domains to have the greatest impact on overall subjective wellbeing. She reinforces this notion stating:

Domain-specific evaluations of subjective QOL are necessary as well as global assessments of QOL if intervention effects are to be understood properly. Service interventions need to be targeted on specific domains to produce the most noticeable effects (Evans, 2007, p. 349).

In this regard, factors of the service user's life (such as their aspirations, feelings of resignation, social connectedness) in addition to symptom management must be considered for the enhancement of QOL. Social workers are therefore required to advocate and practise in a manner that is holistic and understands service user needs and aspirations, in relation to the service user's own perceptions of subjective wellbeing.

\section{Conclusion}

The application of a QOL framework to social work practice, as advocated in this article, recognises the individual's feelings about what constitutes the 'good life' for them, responds to what is important to individuals, recognises ways the individual wants to live, ensures opportunities for personal growth and wellbeing are available and, finally, improves social inclusion and social involvement of all service users (Brown \& Brown, 2003). These concepts draw direct parallels to the current influences on mental health service delivery presented here, such as recovery, social inclusion, community engagement and self-determination. For this reason the authors contend that utilising a QOL framework enhances both the practice and impact of mental health social work interventions. The article concludes that understanding subjective wellbeing ensures that the practice of mental health social work is reflective of the values and life judgements of service users and not those of the organisation, bureaucracy or individual social workers.

\section{References}

Andrews, F. M., \& Withey, S. B. (1976). Social indicators of well-being: Americans' perception of life quality. New York: Plenum Press.

Brown, I., \& Brown, R. I. (2003). Quality of life and disability: An approach for community practitioners. London: Jessica Kingsley Publishers.

Brown, R. I., \& Brown, I. (2005). The application of quality of life. Journal of Intellectual Disability Research, 49(10), 718-727.

Campbell, A., Converse, P. E., \& Rodgers, W. L. (1976). The quality of American Life: Perceptions, evaluations and satisfactions. New York: Russell Sage Foundation.

Connolly, M., \& Ward, T. (2008). Navigating human rights across the life course. Child and Family Social Work, 13, 348-356. 
Cummins, R. A. (1998). The second approximation to an international standard for life satisfaction. Social Indicators Research, 43, 307-334.

Cummins, R. A. (2000). Objective and subjective quality of life. Social Indicators Research, 51, 55-72.

Diener, E. (1984). Subjective well-being. Psychological Bulletin, 95(3), 542-575.

Diener, E., \& Lucas, R. E. (1999). Personality and subjective well-being. In D. Kahneman, E. Diener \& N. Schwarz (Eds.), Well-being: The foundations of hedonic psychology (pp. 213-229). New York: Russell Sage Foundation.

Diener, E., \& Suh, E. (1997). Measuring quality of life: Economic, social, and subjective indicators. Social Indicators Research, 189-216.

Diener, E., Suh, E., \& Oishi, S. (1997). Recent findings on subjective well-being. Indian Journal of Clinical Psychology.

Evans, S. (2007). Quality of life in mental health services. In M. S. Ritsner \& A. G. Awad (Eds.), Quality of life impairments in schizophrenia, mood and anxiety disorders (pp. 333-353). Dordrecht: Springer.

Frese, F., Stanley, J., Kress, K., \& Vogel-Scibilia, S. (2003). Integrating evidence-based practices and the recovery model. In R. Drake \& H. Goldman (Eds.), Evidence-based practices in mental health care (pp.21-29). Arlington: American Psychiatric Association.

Frisch, M. B. (2000). Improving mental and physical health care through quality of life therapy and assessment. In E. Diener \& D. R. Rahtz (Eds.). Advances in quality of life theory and research (pp.207-241). Dordrecht: Kluwer Academic Publishers.

Headey, B., \& Wearing, A. (1992). Understanding happiness: A theory of subjective well-being. Melbourne: Longman Cheshire.

Keith, K. D. (2007). Quality of life. In A. Carr, G. O'Reilly, P. Noonan Walsh \& J. McEvoy (Eds.), The handbook of intellectual disability and clinical psychology practice (pp. 143-168). London: Routledge Taylor \& Francis Group.

Matthewson, P. (2007). Professional leadership in mental health social work. Social Work Review, 19(3), 388-47.

Mental Heath Advocacy Coalition. (2008). Destination: Recovery Te Unga ki Uta, Te Oranga. Auckland: Mental Health Foundation of New Zealand.

Mental Health Commission. (1998). Blueprint for Mental Health Services in New Zealand: How things need to be. Wellington: Mental Health Commission.

Mental Health Commission. (2001). Recovery competencies for New Zealand mental health workers. Wellington: Mental Health Commission.

Mental Health Commission. (2004). Report on progress 2002-2003: Towards implementing the Blueprint for Mental Health Services. Wellington: Mental Health Commission.

Mental Health Commission. (2004a). Our lives in 2014: A recovery vision from people with experience of mental illness for the second mental health plan and the development of the health and social sectors. Wellington: Mental Health Commission.

Mental Health Commission. (2007). Te harerenga mo te whakaoranga 1996-2006: The journey of recovery for the New Zealand mental health sector. Wellington: Mental Health Commission.

Mental Health Commission. (2009). Mental health and social inclusion: Concepts and measurements. Wellington: Mental Health Commission.

Ministry of Health. (2008). Let's get real: Real skills for people working in mental health and addiction. Wellington: Ministry of Health.

Ministry of Social Policy. (2001). The social development approach. Wellington: Ministry of Social Policy.

O'Brien. J. (1993). Supported living: What's the difference? Syracuse: Responsive Systems.

Phillips, R. (2008). A right to a risk filled life: Understandings and analysis of the risk discourse for consumers in mental health. Unpublished masters thesis: Massey University.

Reamer, F. (2005). Social work values and ethics: Reflections on the profession's odyssey. Advances in Social Work, 6(1), 24-32.

Renouf, N., \& Bland, R. (2005). Navigating stormy waters: Challenges and opportunities for social work in mental health. Australian Social Work, 58(4), 419-430.

Rogers, A., \& Pilgrim, D. (1996). Mental health policy in Britain: A critical introduction. Houndmills: Macmillan Press.

Ryan, M., Dowden, C., Healy, B., \& Renouf, N. (2005). Watching the experts: Findings from an Australian study of the expertise in mental health social work. Journal of Social Work, 5(3), 279-298.

Schalock, R. L., Brown, I., Brown, R., Cummins, R. A., Felce, D., Matikka, L. M., et al. (2002). Conceptualization, measurement, and application of quality of life for persons with intellectual disabilities: Report of an international panel of experts. Mental Retardation, 40(6), 457-470.

Schalock, R. L., \& Felce, D. (2004). Quality of life and subjective well-being: Conceptual and measurement issues. In E. Emerson, C. Hatton, T. Thompson \& T. R. Parmenter (Eds.), International handbook on applied research in intellectual disabilities (pp. 261-279). Chichester, West Sussex: John Wiley \& Sons.

Schalock, R. L., \& Verdugo, M. A. (2002). Handbook on quality of life for human service practitioners. Washington, DC: American Association on Mental Retardation.

Warren, H. (1996). The hard end of community care. Auckland: Auckland University Press. 